\title{
The prevalence and mechanism of fluoroquinolone resistance in Escherichia coli isolated from swine farms in China
}

Ping Cheng ${ }^{1 \dagger}$, Yuqi Yang ${ }^{2 \dagger}$, Fulei $\mathrm{Li}^{1}$, Xiaoting $\mathrm{Li}^{1}$, Haibin Liu' ${ }^{1}$, Saqib Ali Fazilani ${ }^{1}$, Wenxin Guo ${ }^{3}$, Guofeng Xu ${ }^{4}$ and Xiuying Zhang ${ }^{1 *}$ (D)

\begin{abstract}
Background: It has been demonstrated that swine waste is an important reservoir for resistant genes. Moreover, the bacteria carrying resistant genes and originating from swine feces and wastewater could spread to the external environment. Fluoroquinolones (FQs) are widely used in livestock and poultry for the treatment of bacterial infection. However, resistance to FQs has increased markedly.

Results: In this study, swine feces and wastewater were sampled from 21 swine farms of seven provinces in China to investigate the prevalence of FQ resistance, including plasmid-mediated fluoroquinolone resistance (PMQR) genes and the occurrence of target mutations. All isolates showed moderate rate of resistance to norfloxacin (43.0\%), ciprofloxacin (47.6\%), ofloxacin (47.0\%) and levofloxacin (38.8\%). The percentage of strains resistant to the four FQs antimicrobials was positively correlated with the danofloxacin (DANO) MIC. Among the 74 FQ-resistant isolates, 39 (52.70\%) had mutations in gyrA (S83L and D87 to N, Y, G, or H), 21 (28.38\%) had mutations in parC (S80l and E84K), 2 (2.70\%) had mutations in parE (I355T and L416F), 26 (35.14\%) had mutations in marR (D67N and G103S), 1 (1.35\%) had mutations in acrR (V29G). While, no mutation was found in gyrB. There were 7 (9.46\%) strains carried the gnrs gene, 29 (39.19\%) strains carried the oqXAB gene, and 9 (12.16\%) strains carried the aac (6')-lb-cr gene. In addition, the conjugation assays showed that qnrS, oqxAB and $a a c\left(6^{\prime}\right)-1 b-c r$ could be successfully transferred to E. coli J53 from 4 (57.1\%), 20 (69.0\%) and 5 (55.6\%) donor strains, respectively. There were no qnrA, qnrB, gnrC, gnrD and gepA genes detected.
\end{abstract}

Conclusion: The present study showed that DANO-resistant E. coli strains isolated from swine farms had significant cross-resistance to other four FQs antimicrobials. Further study revealed that the resistance mechanisms of swinederived E. coli to FQs may be attributable to the occurrence of chromosomal mutations ( $g y r A$, parC, parE, marR and acrR genes double-site or single-site mutation) and the presence of PMQR genes (qnrS, oqxAB and aac ( $\left.\left.6^{\prime}\right)-l b-c r\right)$. To the best of our knowledge, one novel mutation marR-D67N was found to be associated with FQ resistance, two mutations parE-L416F and acrR-V29G have never been reported in China.

Keywords: Fluoroquinolone resistance, Escherichia coli, Swine, PMQR, Target mutations

\footnotetext{
* Correspondence: zhangxiuying@neau.edu.cn

${ }^{\dagger}$ Ping Cheng and Yuqi Yang contributed equally to this work.

'Heilongjiang Key Laboratory for Animal Disease Control and Pharmaceutical Development. Faculty of Basic Veterinary Science, College of Veterinary

Medicine, Northeast Agricultural University, 600 Changjiang Road, Xiangfang

District, Harbin, Heilongjiang 150030, P.R. China

Full list of author information is available at the end of the article
}

C C The Author(s). 2020 Open Access This article is licensed under a Creative Commons Attribution 4.0 International License, which permits use, sharing, adaptation, distribution and reproduction in any medium or format, as long as you give appropriate credit to the original author(s) and the source, provide a link to the Creative Commons licence, and indicate if changes were made. The images or other third party material in this article are included in the article's Creative Commons licence, unless indicated otherwise in a credit line to the material. If material is not included in the article's Creative Commons licence and your intended use is not permitted by statutory regulation or exceeds the permitted use, you will need to obtain permission directly from the copyright holder. To view a copy of this licence, visit http://creativecommons.org/licenses/by/4.0/ The Creative Commons Public Domain Dedication waiver (http://creativecommons.org/publicdomain/zero/1.0/) applies to the data made available in this article, unless otherwise stated in a credit line to the data. 


\section{Background}

Antimicrobial resistance has posed an imminent threat to global health, which threatens our ability to treat common infections caused by bacterial organisms [1]. Due to the restricted choice of antimicrobials as well as the dearth of novel classes of antimicrobials emergence, the infections caused by multidrug-resistant bacteria (MRB) are often accompanied by high morbidity and mortality [2]. It is now generally accepted that the emergence and prevalence of MRB is associated with the widespread, unreasonable, and increasing use of antimicrobials. This could raise a potential risk for the selection of bacteria to become resistant and promote the dissemination of antimicrobial-resistant bacteria (ARB) and resistance genes [3].

Animals are regarded as an important reservoir of resistance genes or ARB which could cause bacterial infection in humans [4]. It has been demonstrated that the possibility for transfer of ARB between animals and humans through environment, food chains and direct contact. Therefore, the emergence of ARB originated from animals have become a growing area of concern. As a common member and the most prevalent enteric bacteria in the intestinal tract of animals and humans, E. coli can also be associated with animal and human infectious diseases due to their zoonotic potential [5, 6]. Hence, the level of resistance in commensal E. coli is regarded as a good indicator for potential selection pressure exerted by regular use of antimicrobials and for investigation of resistance problems in pathogenic bacteria [3, 7].

As a series of synthetic and broad-spectrum antimicrobial agents, FQs possess the bactericidal activity, which can prevent the bacterial cell growth by inhibiting the activities of DNA gyrase and DNA topoisomerase IV, interfering with DNA replication, recombination and repair. Moreover, with the advantages of high bioavailability and low incidence of adverse effects, FQs are widely used in the treatment of a variety of bacterial infections and parasitic diseases $[8,9]$. The purpose of promoting the economic benefits by limiting the mortality of animals, improving feed efficiency and stimulating the uniformity between animals has resulted in the increase use of FQs antimicrobials in farms with the inevitable risk of emerging resistance [10].

FQ resistance in enterobacteriaceae was commonly thought to be chromosome-mediated through mutations in the genes encoding DNA gyrase (gyrA and $g y r B$ ), topoisomerase IV (parC and parE) and the operons of endogenous transmembrane efflux pump AcrAB-TolC (marR and $a c r R$ ), until the PMQR was found in 1998 $[11,12]$. The mutations in $\operatorname{gyr} A, \operatorname{gyr} B, \operatorname{par} C$ and $\operatorname{parE}$ associated with FQ resistance are often located in a region known as the fluoroquinolone resistance determining region (QRDR), which can decrease the affinity of the mutant enzyme-DNA complex to FQs antimicrobials [13]. The mutations in $\operatorname{marR}$ and $a c r R$ can accelerate the efflux of FQs antimicrobials from the bacterial cytoplasm by increasing the expression of AcrAB-TolC [11]. As alternative mediators of FQ resistance, PMQR was first reported in Klebsiella pneumoniae [12]. Importantly, five major groups of Qnr determinants (QnrA, QnrB, QnrC, $Q n r D$, and $Q n r S)$ that encode DNA gyrase protection proteins were identified, which were regarded to have the potential to reduce the susceptibility to FQs and lead to resistance. Efflux pumps (oq $x A B$ and qepA) and a variant of aminoglycoside-modifying enzyme $a a c\left(6^{\prime}\right)-I b$ $\mathrm{cr}$ were proven to be two additional PMQR determinants in previous study $[14,15]$.

The aims of this study were to examine the susceptibility of $E$. coli strains isolated from several swine farms in China to norfloxacin, ciprofloxacin, ofloxacin and levofloxacin, to analyze the correlation between the susceptibility of the strains to the four FQs antimicrobials and the resistance to DANO, to investigate the prevalence of PMQR genes ( $q n r A, q n r B, q n r S$, $q e p A, o q x A B, q n r C, q n r D$ and $\left.a a c\left(6^{\prime}\right)-I b-c r\right)$ and the occurrence of chromosomal mutations in $g y r A, \operatorname{gyr} B$, parC, paE, marR and acrR among the FQ-resistant E. coli strains.

\section{Results}

From July 2014 to March 2017, a total of 1222 E. coli were recovered from swine feces (1000) and wastewater (222). Isolates were collected from Heilongjiang $(n=$ $404)$, Jilin $(n=263)$, Liaoning $(n=227)$, Henan $(n=249)$, Shandong $(n=30)$, Hubei $(n=20)$, and Yunnan $(n=29)$ provinces of China. In this study, a total of $479 \mathrm{E}$. coli isolates were selected for further study, which cover the MIC distribution range $(0.0075->128 \mu \mathrm{g} / \mathrm{mL})$ of DANO. (as shown in Table S1).

\section{Comparisons of antimicrobial resistance in isolates}

The results of the antimicrobial susceptibility testing were shown in Table 1, all isolates showed moderate rate of resistance to norfloxacin (43.0\%), ciprofloxacin (47.6\%), ofloxacin (47.0\%) and levofloxacin (38.8\%). As shown in Fig. 1, the percentage of strains resistant to ciprofloxacin $(r=0.8775, P<0.0001)$, ofloxacin $(r=$ 0.8930, $P<0.0001)$, levofloxacin $(r=0.8613, P<0.0001)$ and norfloxacin $(r=0.8323, P<0.0001)$ was positively correlated with the degree of resistance to DANO.

A total of $74 \mathrm{E}$. coli strains resistant to the four FQs antimicrobials were selected for further study to determine the prevalence of PMQR genes and the occurrence of target mutations in QRDR. 
Table 1 Prevalence of resistance to FQs antimicrobials in swine-derived E. coli isolates of different DANO MICs

\begin{tabular}{|c|c|c|c|c|c|c|c|c|c|c|}
\hline Antimicrobials & DANO MIC $(\mu \mathrm{g} / \mathrm{mL})$ & $\mathrm{HLJ}$ & $J \mathrm{~L}$ & LN & SD & $\mathrm{HN}$ & $\mathrm{HB}$ & YN & Resistance (\%) & Total \\
\hline \multirow[t]{7}{*}{ Norfloxacin } & $\geq 128$ & $27 / 34$ & $26 / 27$ & $24 / 24$ & & $26 / 27$ & $1 / 1$ & $1 / 1$ & $92.11 \%(105 / 114)$ & \\
\hline & 64 & $13 / 16$ & $11 / 14$ & $11 / 11$ & & $10 / 10$ & & & $88.24 \%(45 / 51)$ & \\
\hline & 32 & $9 / 15$ & $8 / 12$ & $10 / 10$ & $1 / 2$ & $6 / 6$ & & & $75.56 \%(34 / 45)$ & \\
\hline & 16 & $1 / 10$ & $1 / 10$ & $1 / 10$ & $7 / 10$ & $3 / 10$ & & & $26 \%(13 / 50)$ & \\
\hline & $8^{\mathrm{a}}$ & $0 / 7$ & $0 / 6$ & $2 / 7$ & & $0 / 7$ & & $0 / 2$ & $6.9 \%(2 / 29)$ & \\
\hline & $4-0.5$ & $4 / 24$ & $0 / 18$ & $2 / 20$ & $1 / 6$ & $0 / 18$ & $0 / 15$ & $0 / 11$ & $6.25 \%(7 / 112)$ & \\
\hline & $\leq 0.25$ & $0 / 20$ & $0 / 17$ & $0 / 14$ & $0 / 3$ & $0 / 18$ & $0 / 4$ & $0 / 2$ & $0(0 / 78)$ & $43.00 \%(206 / 479)$ \\
\hline \multirow[t]{7}{*}{ Ciprofloxacin } & $\geq 128$ & $28 / 34$ & $26 / 27$ & $24 / 24$ & & $26 / 27$ & $1 / 1$ & $1 / 1$ & $92.98 \%(106 / 114)$ & \\
\hline & 64 & $13 / 16$ & $11 / 14$ & $11 / 11$ & & $10 / 10$ & & & $88.24 \%(45 / 51)$ & \\
\hline & 32 & $10 / 15$ & $8 / 12$ & $10 / 10$ & $1 / 2$ & $6 / 6$ & & & $77.78 \%(35 / 45)$ & \\
\hline & 16 & $1 / 10$ & $5 / 10$ & $5 / 10$ & $10 / 10$ & $7 / 10$ & & & $56 \%(28 / 50)$ & \\
\hline & $8^{\mathrm{a}}$ & $0 / 7$ & $1 / 6$ & $4 / 7$ & & $1 / 7$ & & $0 / 2$ & $20.69 \%(6 / 29)$ & \\
\hline & $4-0.5$ & $4 / 24$ & $1 / 18$ & $2 / 20$ & $1 / 6$ & $0 / 18$ & $0 / 15$ & $0 / 11$ & $7.14 \%(8 / 112)$ & \\
\hline & $\leq 0.25$ & $0 / 20$ & $0 / 17$ & $0 / 14$ & $0 / 3$ & $0 / 18$ & $0 / 4$ & $0 / 2$ & $0(0 / 78)$ & $47.60 \%(228 / 479)$ \\
\hline \multirow[t]{7}{*}{ Ofloxacin } & $\geq 128$ & $26 / 34$ & $26 / 27$ & $24 / 24$ & & $26 / 27$ & $1 / 1$ & $1 / 1$ & $91.23 \%(104 / 114)$ & \\
\hline & 64 & $12 / 16$ & $12 / 14$ & $10 / 11$ & & $10 / 10$ & & & $86.27 \%(44 / 51)$ & \\
\hline & 32 & $10 / 15$ & $8 / 12$ & $9 / 10$ & $1 / 2$ & $6 / 6$ & & & $75.56 \%(34 / 45)$ & \\
\hline & 16 & $1 / 10$ & $3 / 10$ & $4 / 10$ & $10 / 10$ & $7 / 10$ & & & $50 \%(25 / 50)$ & \\
\hline & $8^{\mathrm{a}}$ & $0 / 7$ & $1 / 6$ & $3 / 7$ & & $3 / 7$ & & $0 / 2$ & $24.14 \%(7 / 29)$ & \\
\hline & $4-0.5$ & $4 / 24$ & $1 / 18$ & $4 / 20$ & $1 / 6$ & $1 / 18$ & 0/15 & $0 / 11$ & $9.82 \%(11 / 112)$ & \\
\hline & $\leq 0.25$ & $0 / 20$ & $0 / 17$ & $0 / 14$ & $0 / 3$ & $0 / 18$ & $0 / 4$ & $0 / 2$ & $0(0 / 78)$ & $47.00 \%(225 / 479)$ \\
\hline \multirow[t]{7}{*}{ Levofloxacin } & $\geq 128$ & $24 / 34$ & $25 / 27$ & $23 / 24$ & & $26 / 27$ & $1 / 1$ & $1 / 1$ & $87.72 \%(100 / 114)$ & \\
\hline & 64 & $9 / 16$ & $9 / 14$ & 9/11 & & $10 / 10$ & & & $72.55 \%(37 / 51)$ & \\
\hline & 32 & $3 / 15$ & $7 / 12$ & $4 / 10$ & $1 / 2$ & $5 / 6$ & & & $44.44 \%(20 / 45)$ & \\
\hline & 16 & $1 / 10$ & $0 / 10$ & $2 / 10$ & $9 / 10$ & $5 / 10$ & & & $34 \%(17 / 50)$ & \\
\hline & $8^{a}$ & $0 / 7$ & $0 / 6$ & $3 / 7$ & & $2 / 7$ & & $0 / 2$ & $17.24 \%(5 / 29)$ & \\
\hline & $4-0.5$ & $4 / 24$ & $0 / 18$ & $2 / 20$ & $1 / 6$ & $0 / 18$ & $0 / 15$ & $0 / 11$ & $6.25 \%(7 / 112)$ & \\
\hline & $\leq 0.25$ & $0 / 20$ & $0 / 17$ & $0 / 14$ & $0 / 3$ & $0 / 18$ & $0 / 4$ & $0 / 2$ & $0(0 / 78)$ & $38.83 \%(186 / 479)$ \\
\hline
\end{tabular}

Note: DANO Danofloxacin, HLJ Heilongjiang, JL Jilin, LN Liaoning, SD Shandong, HN Henan, HB Hubei, YN Yunan; ${ }^{\text {a }}$, the susceptibility breakpoint of DANO against swine-derived E. coli [5]

\section{Detection of Fluoroquinolone resistance-associated mutations}

As shown in Tables 2 and 3, among the 74 E. coli isolates, no mutations were found in $g y r B$. Alterations in the gyrA gene were detected in 39 (52.7\%) of the 74 E. coli isolates. There were five types of mutations observed in the FQ resistance determining region (QRDR) of gyrA: $32(82.1 \%$ of the 39 gyrA mutated isolates) isolates had S83L and D87N, 2 (5.1\%) had S83L and D87Y, 1 (2.6\%) had S83L and D87H, 1 (2.6\%) had S83L and D87G, as well as $3(7.7 \%)$ had S83L. Twenty-one strains $(28.4 \%)$ carried mutations in the QRDR of parC: 18 strains (85.7\%) had S80I, 2 (9.5\%) had S83L and E84K and 1 (4.8\%) had E84K. Twenty-six strains (35.1\%) carried mutations in marR: 25 strains $(96.2 \%)$ had G103S and 1 (3.8\%) had D67N and G103S. Two strains (2.7\%) carried double parE mutations as: I355T and L416F. One strain carried mutation in $a c r R$, the mutation was V29G. The original dataset was provided in Table S2, and the Gel electrophoresis of the positive PCR product was provided in Figure S1.

\section{Prevalence of plasmid-mediated Fluoroquinolone- resistance genes}

As shown in Fig. 2, among the 74 E. coli isolates, $o q x A B$ was the most prevalent PMQR genes, 29 (39.19\%) strains carried the $o q x A B$ gene. The number of isolates harbouring qnrS gene was 7 (9.46\%). Four isolates (5.4\%) were detected to co-harbour oqxAB, qnrS and aac (6')$\mathrm{Ib}-\mathrm{cr}$ gene. One strains (1.4\%) co-harbour $q h r S$ and $o q x A B$. The number of strains co-harbour $o q x A B$ and 


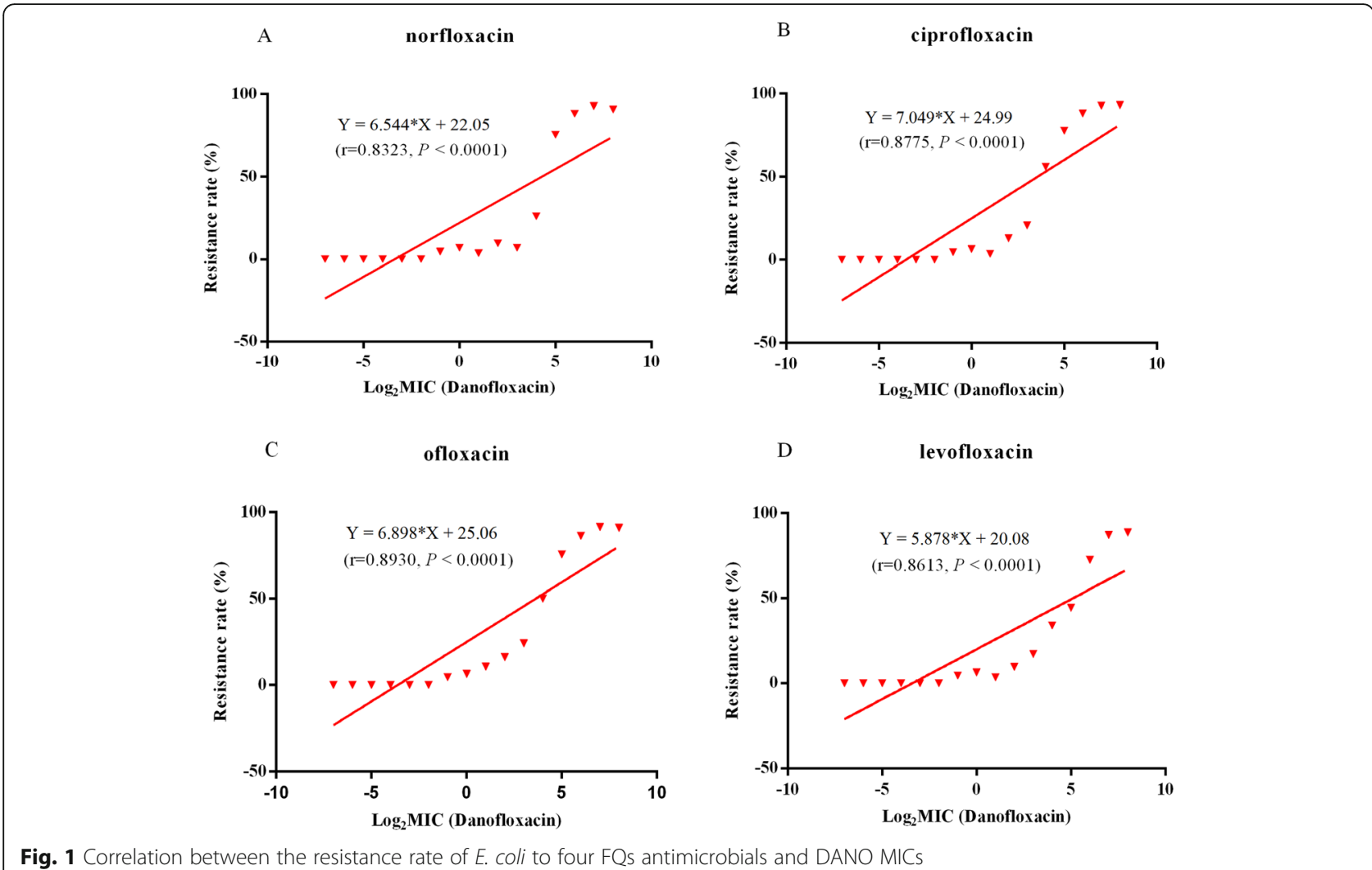

$a a c\left(6^{\prime}\right)-I b-c r$ was $2(2.7 \%)$. Nine strains $(12.16 \%)$ were positive for $a a c\left(6^{\prime}\right)-I b-c r$ gene. But no strains were found to be positive for $q n r A, q n r B, q n r C$, $q n r D$ and $q e p A$. The Gel electrophoresis of the PMQR genes was provided in Figure S2.

\section{Conjugative transfer of PMQR genes from swine farms}

Conjugation experiments were carried out in this study to assess the transferability and the dissemination risk of PMQR genes in swine farm. The results of conjugation assays showed that qnrS, oqxAB and aac (6')-Ib-cr could be successfully transferred to $E$. coli 553 from 4 (57.1\%), $20(69.0 \%)$ and $5(55.6 \%)$ donor strains, respectively, at frequencies of $3.5 \times 10^{-8}$ to $4.7 \times 10^{-5}, 2.1 \times 10^{-9}$ to
$5.3 \times 10^{-6}$ and $1.8 \times 10^{-8}$ to $5.8 \times 10^{-4}$ transconjugants/ recipient, respectively. The transconjugants were also FQ-resistant, but they showed low-level resistance to FQs antimicrobials as compared with donor strains.

\section{Discussion}

The frequencies of resistance to $\mathrm{FQs}$ among E. coli strains isolated from humans and animals have been reported to be rising year by year in China, which might partly be attributable to the unreasonable and increasing use of this class of antimicrobial in food-producing animals $[16,17]$. In the present study, the results of susceptibility test revealed that the 479 E. coli isolates collected from several swine farms in China and covering the

Table 2 The Sorting Intolerant From Tolerant (SIFT) scores of different mutations

\begin{tabular}{|c|c|c|c|c|c|c|c|c|c|c|c|c|}
\hline \multirow{3}{*}{$\frac{\text { Genes }}{\text { Sites }}$} & \multicolumn{9}{|c|}{ Topoisomerases and gyrase mutations } & \multicolumn{3}{|c|}{$\underline{\text { Efflux-related mutations }}$} \\
\hline & \multicolumn{5}{|l|}{ gyra } & \multicolumn{2}{|l|}{ parc } & \multicolumn{2}{|l|}{ parE } & \multicolumn{2}{|l|}{ marR } & \multirow{2}{*}{$\frac{a c r h}{29^{b}}$} \\
\hline & 83 & 87 & 87 & 87 & 87 & 80 & 84 & 355 & $416^{b}$ & $67^{\mathrm{a}}$ & 103 & \\
\hline \multirow[t]{2}{*}{ Amino acid alterations } & $\mathrm{S}$ & $\mathrm{D}$ & $\mathrm{D}$ & D & $\mathrm{D}$ & S & $\mathrm{E}$ & । & $\mathrm{L}$ & $\mathrm{D}$ & G & V \\
\hline & $\mathrm{L}$ & N & Y & G & $\mathrm{H}$ & I & K & $\mathrm{T}$ & $\mathrm{F}$ & $\mathrm{N}$ & $S$ & G \\
\hline Proven Scores & -4.2 & -4.6 & -8.3 & -6.5 & -6.3 & -5.8 & -3.9 & 2.9 & -3.9 & -4.4 & 1.4 & -6.3 \\
\hline Prediction & DT & DT & DT & DT & DT & DT & DT & NT & DT & DT & NT & DT \\
\hline
\end{tabular}

Note: Score thresholds for prediction: Default threshold is -2.5 , variant with a score equal to or below -2.5 are considered "deleterious", variant with a score above -2.5 are considered "neutral"; QRDR fluoroquinolone resistance determining region, DT Deleterious, NT Neutral; ${ }^{\text {a }}$ The novel mutation was found to be associated with fluoroquinolone resistance; ${ }^{\mathrm{b}}$ The mutation has never been reported in China 
Table 3 Putative FQ resistance mutations and mutation rate

\begin{tabular}{|c|c|c|c|c|c|}
\hline \multirow{2}{*}{$\begin{array}{l}\text { NO of isolates and } \\
\text { DANO MIC }(\mu \mathrm{g} / \mathrm{mL})\end{array}$} & \multicolumn{3}{|c|}{ Topoisomerases and gyrase mutations } & \multicolumn{2}{|c|}{ Efflux-related mutations } \\
\hline & gyrA & parC & parE & mark & $a c r R$ \\
\hline $13(128) ; 2(64) ;$ & S83L, D87N & None & None & None & None \\
\hline $2(128) ; 1(64)$ & S83L, D87N & S801 & None & None & None \\
\hline $5(128) ; 3(64)$ & S83L, D87N & $\mathrm{S} 80 \mathrm{l}$ & None & G103S & None \\
\hline $2(128) ; 1$ (32) & S83L, D87N & None & None & G103S & None \\
\hline $2(128) ; 1$ (32); 2 (8) & None & $\mathrm{S} 80 \mathrm{l}$ & None & G103S & None \\
\hline $1(128) ; 1$ (64) & S83L, D87N & S80l & I355T,L416F & None & None \\
\hline $1(128)$ & None & $\mathrm{S} 80 \mathrm{l}$ & None & G103S & V29G \\
\hline $1(64)$ & S83L, D87Y & $\mathrm{S} 80 \mathrm{l}$ & None & G103S & None \\
\hline $1(64)$ & S83L, D87H & None & None & G103S & None \\
\hline $1(64)$ & S83L, D87N & None & None & D67N,G103S & None \\
\hline $1(32)$ & S83L, D87Y & $\mathrm{S} 80 \mathrm{l}$ & None & None & None \\
\hline $2(32)$ & $\mathrm{S} 83 \mathrm{~L}$ & None & None & G103S & None \\
\hline $1(32)$ & $\mathrm{S} 83 \mathrm{~L}$ & None & None & None & None \\
\hline $1(32)$ & S83L, D87G & None & None & None & None \\
\hline $1(16)$ & None & S80I, E84K & None & None & None \\
\hline $1(16)$ & None & E84K & None & None & None \\
\hline $1(1)$ & None & $\mathrm{S} 80 \mathrm{l}$ & None & None & None \\
\hline $1(32) 1(4) ; 1(1)$ & None & None & None & G103S & None \\
\hline mutation rate & $52.70 \%$ & $28.38 \%$ & $2.70 \%$ & $35.14 \%$ & $1.35 \%$ \\
\hline
\end{tabular}

Note: DANO Danofloxacin, NO number

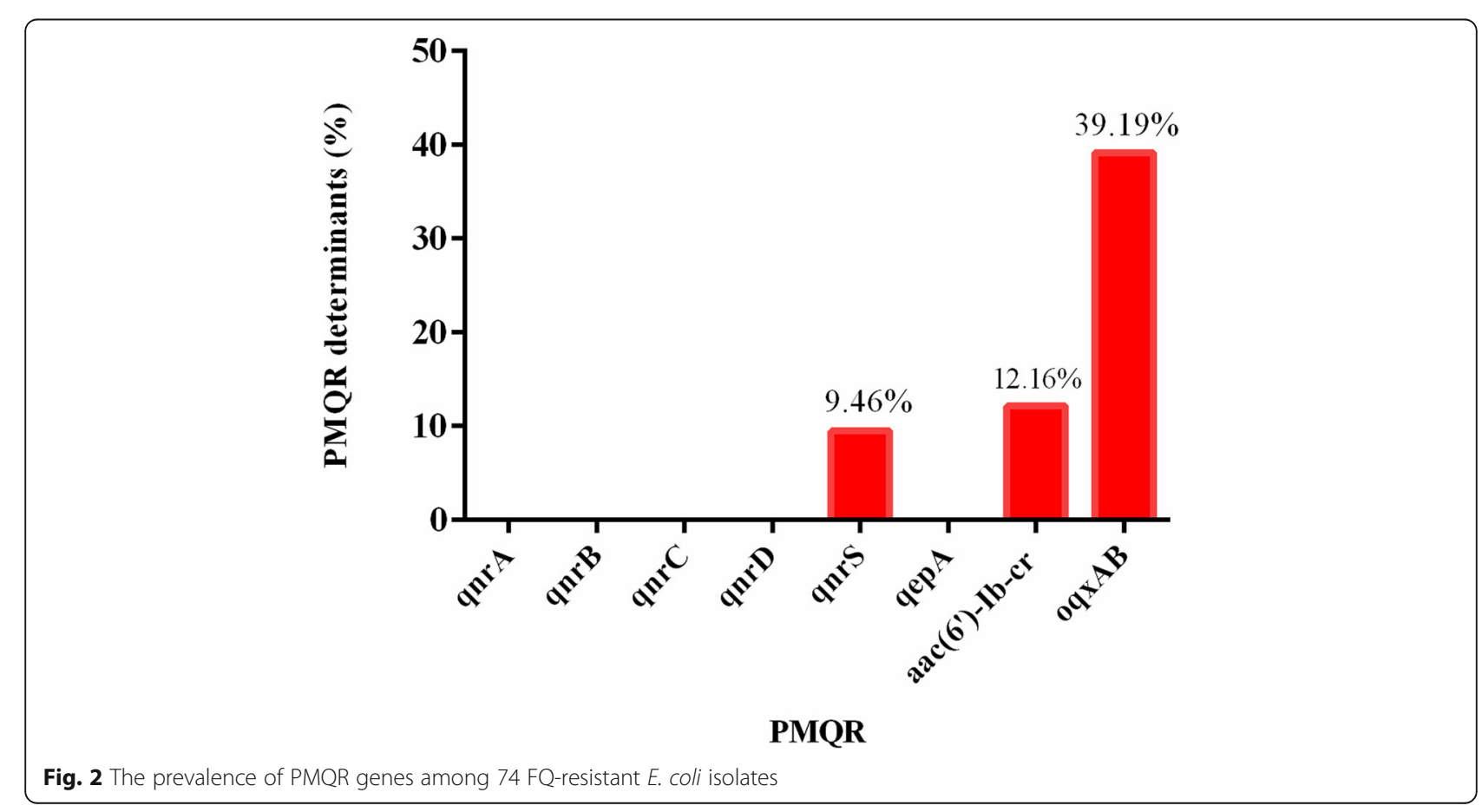


MIC distribution range $(0.0075->128 \mu \mathrm{g} / \mathrm{mL})$ of DANO showed moderate rate of resistance to other four FQs antimicrobials (ciprofloxacin, ofloxacin, levofloxacin and norfloxacin). Further analysis showed that the percentage of strains resistant to the four FQs antimicrobials was positively correlated with the degree of resistance to DANO. In fact, ofloxacin and norfloxacin are not approved for veterinary uses, which are used in humans to prevent bacterial infection. But ciprofloxacin, norfloxacin and DANO have been used widely in veterinary medicine in China $[18,19]$. It is well known that the indiscriminate use of FQs antimicrobials in humans and animals could raise a potential risk for the selection and acceleration the emergence of FQ resistance [4]. A previous report revealed very high rate of ciprofloxacin (75.2\%), enrofloxacin (81.0\%) and levofloxacin (70.5\%) resistance in the E. coli isolated from diseased foodproducing animals in Guangdong province, China [20]. The higher resistant rate could be due to the different origin of $E$. coli strains compared with this study.

The rapid development of FQ resistance is commonly acknowledged to be due to the widespread dissemination of PMQR determinants. Though PMQR determinants usually result in low-level resistance to FQs antimicrobials, the presence of PMQR determinants can promote and accelerate the occurrence of target mutations on the chromosome which mediate high-level resistance [21]. Some surveys have reported a high prevalence of PMQR determinants and occurrence of mutations in the QRDR among E. coli and Salmonella strains isolated from humans and food-producing animals in China [22, 23]. In this study, a high prevalence (60.8\%) of PMQR determinants (qnrS, oqxAB and $\left.a a c\left(6^{\prime}\right)-I b-c r\right)$ was found in the 74 FQ-resistant $E$. coli, and the most prevalent PMQR gene was oqxAB (39.19\%), which were in line with the finding of a previous study [24]. In the present study, the $a a c\left(6^{\prime}\right)-I b-c r$ gene $(12.16 \%)$ was also a prevalent PMQR gene, similarly to the result of a study from China in which $o q x A B$ was not analyzed [25]. The qnrS (9.46\%) was predominantly present among the qnr-type genes in this study, which was consistent with previous study $[22,25]$. Our results supported previous findings that the prevalence of $a a c\left(6^{\prime}\right)-I b-c r$ was higher than that of $q n r$ [26]. There were no $q n r A, q n r B, q n r C, q n r D$ and qepA genes detected in this study.

The mutation frequency (95.9\%) of the 74 FQ-resistant $E$.coli in this study was higher than that found in 14 qur-positive E. coli strains isolated from farm animals (35.7\%) [22, 27]. Similar to our findings, it was reported that 39 nalidixic acid-resistant E. coli strains isolated from diseased farm animals had a high mutation frequency $(100 \%)[16,28]$. The different criteria used for isolates selection may be responsible for the differences among these studies. In this study, a total of 39 (52.7\%) strains carried mutations in $g y r A$, including S83L and D87 to $\mathrm{N}$ or $\mathrm{Y}$. These mutations at positions 83 and 87 have previously been detected in FQ-resistant E. coli strains [20]. Among the isolates with mutations, the most frequent mutations were at codons 83 and 87 in gyrA in the QRDR, and the most common type of amino acid substitution were S83L and D87N in gyrA, the results were consistent with previous study [29, 30]. It has been demonstrated that double-mutant (S83L and D87N) enzyme-DNA complexes had a lower affinity for FQs antimicrobials than wild-type complexes [13].

Though there were no mutations in $\operatorname{gyr} B$ among 74 FQ-resistant $E$. coli strains, we could not ignore the possibility of $\operatorname{gyr} B$ mutations in $E$. coli strains resistant to FQs, but previous study have also reported their absence [31]. Two different mutations were found in $\operatorname{parC}$, including $24(32.4 \%)$ strains carried mutations altering amino acid S80I and $3(4.1 \%)$ strains carried E84K. The two mutations have been previously demonstrated to be associated with FQ resistance in E. coli [20]. Four strains had mutations in parE (I355T and L416F) which have been detected in FQ-resistant $E$. coli isolated from swine fecal samples in Korea [32]. Only two parE mutations, $\mathrm{L} 445 \mathrm{H}$ and $\mathrm{L} 416 \mathrm{~F}$ have been proven to be associated with FQ resistance in E. coli [14,33]. To the best of our knowledge, L416F mutation has never been reported in China.

It has been demonstrated that the mutations in the repressor proteins marR and acrR can result in FQresistance by promoting the expression of the AcrABTolC efflux pump [11]. In the present study, a total of 26 strains with mutations in $\operatorname{marR}, 25$ strains of those carried single mutation (G103S) and 1 strain of those carried two mutations (D67N and G103S). It has been reported that no significant association was found between the mutation marR-G103S and any level of FQ resistance [14]. The mutations in the region of marR (D76G, L78M, and V79I) have been reported to result in FQ resistance [11]. The possible role of novel mutation marR-D67N in FQ-resistant isolate requires further study to reveal. Only one strain carried mutation acrRV29G which was also detected among highly levofloxacin-resistant $E$. coli isolates in previous study. The possible roles of acrR-V29G in FQ resistance may contribute to increased fitness rather than increased levels of resistance [14]. Moreover, some studies have reported that the coexistence of $a c r R$ gene mutations and other known chromosomal mutations in clinical strains of E. coli can lead to high-level FQ resistance [34].

\section{Conclusion}

In summary, DANO-resistant E. coli strains isolated from swine farms had significant cross-resistance to other four FQs antimicrobials, and the percentage of 
strains resistant to other FQs antimicrobials was positively correlated with the degree of resistance to DANO. Furthermore, the resistance mechanisms of swinederived $E$. coli to FQs may be attributable to the occurrence of chromosomal mutations (gyrA, parC, parE, marR and $a c r R$ genes double-site or single-site mutation) and the presence of $\mathrm{PMQR}$ determinants (qnrS, $o q x A B$ and aac (6')-Ib-cr). To the best of our knowledge, one novel mutation marR-D67N was found to be associated with FQ resistance, and two mutations parEL416F and acrR-V29G have never been reported in China.

\section{Methods}

\section{Sampling and bacterial isolates}

From July, 2014 to March, 2017, a total of 300 piggery wastewater samples were collected from 21 swine farms located in different geographic areas of China, including Heilongjiang, Jilin, Liaoning, Henan, Hubei, Shandong and Yunnan province (Table 1). The samples brought to the laboratory were immediately cultured on MacConkey agar at $37^{\circ} \mathrm{C}$ for $18-24 \mathrm{~h}$, and then five colonies with typical $E$. coli morphology were selected from each sample. The bacterial strains were identified using classing biochemical methods and confirmed as E. coli by PCR amplification of $16 S r R N A$ and sequencing. In addition, a total of 1000 E. coli strains were selected from our previous study. All confirmed E. coli isolates were stored at $-80^{\circ} \mathrm{C}$ for further studies.

\section{Antimicrobial susceptibility testing}

For all isolated E. coli, the microdilution broth method in accordance with the guidelines in Clinical and Laboratory Standards Institute (CLSI) document M07-A9 was performed to determine the MICs of DANO. Moreover, the results were interpreted according the breakpoint which was established in the previous study [5]. The antimicrobial susceptibilities of E. coli to ciprofloxacin, ofloxacin, levofloxacin and norfloxacin were determined by disk diffusion method described by European Committee on Antimicrobial Susceptibility Testing (EUCAST). The interpretation of the result was according to EUCAST criteria.

\section{Screening for Fluoroquinolone resistance-associated mutations}

DNA templates of the FQ-resistant $E$. coli isolates were obtained with the Kit (Tiangen) following the manufacturer's instructions. Screening for mutations accounting for FQ resistance including $\operatorname{gyr} A, \operatorname{gyr} B, \operatorname{par} C$, $p a E$, marR and $\operatorname{acr} R$ was carried out by PCR amplification and DNA sequencing. The oligonucleotide primers used, together with details of the specific regions sequenced in each gene were the same as previously described [11].
The amplification products were visualized by agarose gel electrophoresis and ethidium bromide staining to assess the sizes of the gene fragments, and then the positive products were validated with Sanger sequencing. The obtained sequences were analyzed with the Chromas and the amino acid sequences of $\operatorname{gyr} A, \operatorname{gyr} B$, parC, paE, marR and acrR were compared with wildtype $E$. coli $\mathrm{K}-12$ to determine the amino acid changes. Besides, the Sorting Intolerant From Tolerant (SIFT) scores (http://sift.jcvi.org) were calculated by online software to determine whether amino acid changes in $g y r A$, gyrB, parC, paE, marR and $a c r R$ affect protein function. (neutral or deleterious).

\section{Screening for plasmid-mediated Fluoroquinolone- resistance determinants}

Plasmid DNA of the resistant E. coli isolates was obtained with plasmid extraction kit following the manufacturer's instructions. Multiplex PCR was performed for the detection of PMQR genes, including qnrA, qnrB, $q n r S$, qepA, oqxAB, qnrC, qnrD and aac (6')-Ib-cr. The oligonucleotide primers and the details of PCR amplification were used as previously described [35].

\section{Conjugative transfer of PMQR genes}

For assessing the transferability of the PMQR genes in swine farms, conjugation experiment was performed according to method described by Ghosh and Mukherjee [36]. The strains of $q n r S$-positive E. coli, oqxAB-positive E. coli, and a $a a c\left(6^{\prime}\right)-I b-c r$-positive $E$. coli isolates were used as the donors of PMQR genes in conjugation experiments, and E. coli J53 strains with azide resistance was used as recipient. The MacConkey agar plates containing sodium azide $(100 \mu \mathrm{g} / \mathrm{L})$ and ciprofloxacin $(5 \mu \mathrm{g} /$ $\mathrm{mL}$ ) were used to select PMQR genes positive transconjugants. PCR analysis and DNA sequencing were carried out to confirm that transconjugants were derivatives of the recipient strain $E$. coli J53. The transfer frequencies of $q n r S, o q x A B$ and $a a c\left(6^{\prime}\right)-I b-c r$ genes were determined as described in a previous study [37].

\section{Statistical analysis}

Descriptive analyses on percentage and prevalence were performed using functions provided in Excel 2007 (Microsoft Software). To determine the correlation of the resistance rate of $E$. coli to four FQs antimicrobials with the DANO MIC values, Pearson correlation and linear regression analysis were performed by using GraphPad Prism 6 for windows. P-value less than 0.05 was considered statistically significant.

\section{Supplementary information}

Supplementary information accompanies this paper at https://doi.org/10. 1186/s12917-020-02483-4. 
Additional file 1: Table S1. The area distribution of collected swine $E$ coli isolates. Table S2. Putative FQ resistance mutations and the prevalence of PMQR genes in swine-derived E. coli. Figure S1. Gel electrophoresis of the FQ-resistance associated gene on the chromosome in swine-derived E. coli. Figure S2. Gel electrophoresis of the PMQR genes in swine-derived E. coli.

\section{Abbreviations}

FQs: Fluoroquinolones; ARB: Antimicrobial-resistant bacteria; PMQR: Plasmidmediated quinolone resistance; E. coli: Escherichia coli; DANO: Danofloxacin; QRDR: Fluoroquinolone resistance determining region; CLSI: Clinical and Laboratory Standards Institute; EUCAST: European Committee on Antimicrobial Susceptibility Testing; SIFT: Sorting Intolerant From Tolerant

\section{Acknowledgements}

We would like to thank the 21 swine farms located in different geographic areas of China, including Heilongjiang, Jilin, Liaoning, Henan, Hubei, Shandong and Yunnan province for giving permission and help during collecting fecal samples.

\section{Authors' contributions}

$\mathrm{XZ}$ is the corresponding author who conceived and designed the experiments; PC designed the experiments, completed the experiments and draft the manuscript; YY contributed to the conception and design of the experiments; $F L$ and $H L$ collected the samples and performed bacteria isolation; $\mathrm{XL}, \mathrm{WG}$ and $\mathrm{GX}$ performed the analysis and interpretation of the data; SAF modified the language of the manuscript. All authors read and approved the final manuscript.

\section{Funding}

This work was supported by the National Science and Technology Project and the National 13th Five-Year Key R\&D Program Special Project under Grant: 2018 YFD0500306 and 2016YFD0501302. The funders had no role in the design of the study and collection, analysis and interpretation of data and in writing the manuscript.

\section{Availability of data and materials}

The datasets used and analyzed in this study are available from the corresponding author on reasonable request.

\section{Ethics approval and consent to participate}

All experimental work was performed in accordance with the animal ethics guidelines approved by the animal care and ethics committee of Northeast Agricultural University (Heilongjiang Province PR China). Prior to the collection of fecal samples, individual written informed consent for the use of samples was obtained from all owners.

\section{Consent for publication}

Not applicable.

\section{Competing interests}

The authors declare no competing financial interest.

\footnotetext{
Author details

${ }^{1}$ Heilongjiang Key Laboratory for Animal Disease Control and Pharmaceutical Development. Faculty of Basic Veterinary Science, College of Veterinary Medicine, Northeast Agricultural University, 600 Changjiang Road, Xiangfang District, Harbin, Heilongjiang 150030, P.R. China. ${ }^{2}$ Pharmacology Teaching and Research Department, School of Basic Medicine, Guizhou University of Traditional Chinese Medicine, Dongqing Road, University Town, Huaxi District, Guiyang, P.R. China. ${ }^{3}$ Heilongjiang Technical Identification Station of Agricultural products and Veterinary Medicine Feed, Harbin, China. ${ }^{4}$ Inflammation \& Allergic Diseases Research Unit, Affiliated Hospital of Southwest Medical University, Luzhou 646000, Sichuan, China.
}

Received: 12 March 2020 Accepted: 20 July 2020

Published online: 28 July 2020

\section{References}

1. Shen Z, Hu Y, Sun Q, Hu F, Zhou H, Shu L, Ma T, Shen Y, Wang Y, Li J, et al. Emerging carriage of NDM-5 and MCR-1 in Escherichia coli from healthy people in multiple regions in China: a cross sectional observational study. EClinicalMedicine. 2018;6:11-20.

2. Worthington RJ, Melander C. Combination approaches to combat multidrug-resistant bacteria. Trends Biotechnol. 2014;31(3):177-84.

3. van den Bogaard AE, Stobberingh EE. Epidemiology of resistance to antibiotics. Links between animals and humans. Int J Antimicrob Agents. 2000:14(4):327-35.

4. Schwarz S, Kehrenberg C, Walsh TR. Use of antimicrobial agents in veterinary medicine and food animal production. Int J Antimicrob Agents. 2001;17(6):431-7.

5. Yang Y, Zhang Y, Li J, Cheng P, Xiao T, Muhammad I, Yu H, Liu R, Zhang X. Susceptibility breakpoint for Danofloxacin against swine Escherichia coli. BMC Vet Res. 2019;15(1):51.

6. Costa D, Poeta P, Saenz Y, Coelho AC, Matos M, Vinue L, Rodrigues J, Torres $C$. Prevalence of antimicrobial resistance and resistance genes in faecal Escherichia coli isolates recovered from healthy pets. Vet Microbiol. 2008; 127(1-2):97-105.

7. Sáenz $Y$, Zarazaga M, Briñas L, Lantero M, Ruiz-Larrea F, Torres C. Antibiotic resistance in Escherichia coli isolates obtained from animals, foods and humans in Spain. Int J Antimicrob Agents. 2001;18(4):353-8.

8. Sarkozy G. Quinolones: a class of antimicrobial agents. Vet Med. 2001;46(910):257-74.

9. Zhanel GG, Walkty A, Vercaigne L, Karlowsky JA, Embil J, Gin AS, Hoban DJ. The new fluoroquinolones: a critical review. Can J Infect Dis. 1999;10(3):20738.

10. Alcorn T. Antibiotic use in livestock production in the USA. Lancet Infect Dis. 2012;12(4):273-4.

11. Komp Lindgren P, Karlsson A, Hughes D. Mutation rate and evolution of fluoroquinolone resistance in Escherichia coli isolates from patients with urinary tract infections. Antimicrob Agents Chemother. 2003;47(10):3222-32.

12. Martinez-Martinez L, Pascual A, Jacoby GA. Quinolone resistance from a transferable plasmid. Lancet. 1998;351(9105):797-9.

13. Barnard FM, Maxwell A. Interaction between DNA Gyrase and quinolones: effects of alanine mutations at GyrA subunit residues Ser83 and Asp87. Antimicrob Agents Chemother. 2001;45(7):1994-2000.

14. Zayed AF, Essam TM, Hashem A-GM, El-Tayeb OM. 'Supermutators' found amongst highly levofloxacin-resistant $E$. coli isolates: a rapid protocol for the detection of mutation sites. Emerg Microbes Infect. 2015;4(1):e4.

15. Rodríguez-Martínez JM, Cano ME, Velasco C, Martínez-Martínez L, Pascual A. Plasmid-mediated quinolone resistance: an update. J Infect Chemother. 2010;17(2):149-82.

16. Yang $\mathrm{H}$, Sheng $\mathrm{C}$, White DG, Zhao S, Mcdermott $\mathrm{P}$, Walker $\mathrm{R}$, Meng J. Characterization of Multiple-Antimicrobial-Resistant Isolates from Diseased Chickens and Swine in China. J Clin Microbiol. 2004;42(8):3483-9.

17. Xiao YH, Wang J, Li Y, Net obotMNARI. Bacterial resistance surveillance in China: a report from Mohnarin 2004-2005. Eur J Clin Microbiol Infect Dis. 2008;27(8):697-708.

18. Ball P. Adverse drug reactions: implications for the development of fluoroquinolones. J Antimicrob Chemother. 2003;51(Suppl 1):21-7 (90001).

19. Naber GK. Treatment options for acute uncomplicated cystitis in adults. J Antimicrob Chemother. 2000;46(90001):23-7.

20. Liu BT, Liao XP, Yang SS, Wang XM, Li LL, Sun J, Yang YR, Fang LX, Li L, Zhao $\mathrm{DH}$, et al. Detection of mutations in the gyrA and parC genes in Escherichia coli isolates carrying plasmid-mediated quinolone resistance genes from diseased food-producing animals. J Med Microbiol. 2012;61(Pt 11):1591-9.

21. Robicsek A, Jacoby G, Hooper D. The worldwide emergence of plasmidmediated quinolone resistance. Lancet Infect Dis. 2006;6(10):629-40.

22. Yue L, Jiang HX, Liao XP, Liu JH, Li SJ, Chen XY, Chen CX, Lu DH, Liu YH. Prevalence of plasmid-mediated quinolone resistance qnr genes in poultry and swine clinical isolates of Escherichia coli. Vet Microbiol. 2008;132(3-4):414-20

23. Wang YC, Chan JP, Yeh KS, Chang CC, Hsuan SL, Hsieh YM, Chang YC, Lai TC, Lin WH, Chen TH. Molecular characterization of enrofloxacin resistant Actinobacillus pleuropneumoniae isolates. Vet Microbiol. 2010;142(3-4):309-12.

24. Zhao J, Chen Z, Chen S, Deng Y, Liu Y, Tian W, Huang X, Wu C, Sun Y, Sun $Y$, et al. Prevalence and dissemination of oqXAB in Escherichia coli isolates 
from animals, farmworkers, and the environment. Antimicrob Agents Chemother. 2010;54(10):4219-24.

25. Xia L, Li L, Wu C, Liu Y, Tao X, Dai L, Qi Y, Lu L, Shen J. A survey of plasmidmediated fluoroquinolone resistance genes from Escherichia coli isolates and their dissemination in Shandong, China. Foodborne Pathog Dis. 2010; 7(2):207-15.

26. Warburg G, Korem M, Robicsek A, Engelstein D, Moses AE, Block C, Strahilevitz J. Changes in aac (6)-Ib-cr prevalence and Fluoroquinolone resistance in nosocomial isolates of Escherichia coli collected from 1991 through 2005. Antimicrob Agents Chemother. 2009;53(3):1268-70.

27. Zhao X, Xu X, Zhu D, Ye X, Wang M. Decreased quinolone susceptibility in high percentage of Enterobacter cloacae clinical isolates caused only by Qnr determinants. Diagn Microbiol Infect Dis. 2010;67(1):110-3.

28. Lascols C, Robert J, Cattoir V, Bebear C, Cavallo JD, Podglajen I, Ploy MC, Bonnet R, Soussy CJ, Cambau E. Type II topoisomerase mutations in clinical isolates of Enterobacter cloacae and other enterobacterial species harbouring the gnrA gene. Int J Antimicrob Agents. 2007;29(4):402-9.

29. Yang J, Luo Y, Li J, Ma Y, Hu C, Jin S, Ye L, Cui S. Characterization of clinical Escherichia coli isolates from China containing transferable quinolone resistance determinants. J Antimicrob Chemother. 2010;65(3):453-9.

30. Uchida Y, Mochimaru T, Morokuma Y, Kiyosuke M, Fujise M, Eto F, Harada Y, Kadowaki M, Shimono N, Kang D. Geographic distribution of fluoroquinolone-resistant Escherichia coli strains in Asia. Int J Antimicrob Agents. 2010;35(4):387-91.

31. Everett MJ. Contributions of individual mechanisms to fluoroquinolone resistance in 36 Escherichia coli strains isolated from humans and animals. Antimicrob Agents Chemother. 1996;40(10):2380-6.

32. Hu YS, Sook S, Ho PY, Taek PK. Prevalence and mechanism of Fluoroquinolone resistance in Escherichia coli isolated from swine Feces in Korea. J Food Prot. 2017;80(7):1145-51.

33. Breines DM, Ouabdesselam S, Ng EY, Tankovic J, Shah S, Soussy CJ, Hooper DC. Quinolone resistance locus $\mathrm{nfXD}$ of Escherichia coli is a mutant allele of the parE gene encoding a subunit of topoisomerase IV. Antimicrob Agents Chemother. 1997;41(1):175-9.

34. Wang H, Dzink-Fox JL, Chen M, Levy SB. Genetic characterization of highly fluoroquinolone-resistant clinical Escherichia coli strains from China: role of acrR mutations. Antimicrob Agents Chemother. 2001;45(5):1515-21.

35. Ciesielczuk H, Hornsey M, Choi V, Woodford N, Wareham D. Development and evaluation of a Multiplex PCR for Eight Plasmid-Mediated Quinolone Resistance Determinants. J Med Microbiol. 2013;62(Pt_12):1823-7.

36. Ghosh B, Mukherjee M. Emergence of co-production of plasmid-mediated AmpC beta-lactamase and ESBL in cefoxitin-resistant uropathogenic Escherichia coli. Eur J Clin Microbiol Infect Dis. 2016;35(9):1449-54.

37. Liu Y-Y, Wang Y, Walsh T, Yi L-X, Zhang R. Emergence of plasmid-mediated colistin resistance mechanism MCR-1 in animals and human beings in China: a microbiological and molecular biological study. Lancet Infect Dis. 2016;16:161-8

\section{Publisher's Note}

Springer Nature remains neutral with regard to jurisdictional claims in published maps and institutional affiliations.

Ready to submit your research? Choose BMC and benefit from:

- fast, convenient online submission

- thorough peer review by experienced researchers in your field

- rapid publication on acceptance

- support for research data, including large and complex data types

- gold Open Access which fosters wider collaboration and increased citations

- maximum visibility for your research: over $100 \mathrm{M}$ website views per year

At $\mathrm{BMC}$, research is always in progress.

Learn more biomedcentral.com/submissions 